\title{
Impact of ecological environment on maternal parenting style
}

See end of the paper for authors' affiliations BIMLA DHANDA Department of Human Development and Family Studies, College of Home Science, C.C.S. Haryana Agricultural University, HISAR (HARYANA) INDIA

Email : bimladhanda@gmail.com
ABSTRACT : The study was conducted in Hisar district of state Haryana. The objective of the study was to assess the impact of ecological perspectives on maternal parenting style. A sample comprised of 100 mothers of children in the age group of 7-8 years. The results revealed that associations. It was significantly associated with father education, mother education, and caste. It was also found maternal parenting was significantly associated with home environment and its all the aspects viz., responsivity, encouragement of maturity, emotional climate, learning materials and opportunities, enrichment, and family companionship except family integration and physical environment. Half of the mothers were authoritative and authoritarian followed by permissive mothers.

KEY WORDS: Maternal parenting, Socio-personal, Home environment

- HOW TO CITE THIS PAPER : Saini, Varsha and Dhanda, Bimla (2016). Impact of ecological environment on maternal parenting style. Asian J. Home Sci., 11 (1) : 35-39, DOI: 10.15740/HAS/AJHS/ 11.1/35-39. 